\title{
Quantification of Ethanedinitrile in Air Using a New and Accurate Gas Chromatography Method
}

\author{
Sam E. Brierley ${ }^{1}$, Anthony R. Adlam ${ }^{1}$ and Matthew K. D. Hall ${ }^{1,2, *}$ \\ 1 The New Zealand Institute for Plant \& Food Research Limited, Private Bag 11600, Palmerston North 4442, \\ New Zealand; sam.brierley@plantandfood.co.nz (S.E.B.); anthony.adlam@plantandfood.co.nz (A.R.A.) \\ 2 Apreso, PO Box 2407, Palmerston North 4442, New Zealand \\ * Correspondence: matt@apreso.co.nz; Tel.: +61-422-938-529
}

Received: 5 November 2018; Accepted: 13 December 2018; Published: 20 December 2018

check for updates

\begin{abstract}
Compared to previously tested fumigants such as methyl bromide, sulfuryl fluoride and phosphine; ethanedinitrile (EDN) is a new fumigant which is being trialled around the world as a pre-plant soil treatment and as a quarantine and pre-shipment (QPS) treatment of commodities. To collect the data necessary to assess the effectiveness of this fumigant, an accurate analytical method is needed across a wide concentration range. We reviewed the methods of detection for EDN described in recently published fumigation studies and have developed and validated a method to quantify EDN in air using a gas chromatograph equipped with a flame ionization detector (GC-FID). Our tested method has a linearity, precision, accuracy, limit of detection (LOD) and limit of quantification (LOQ) of $\mathrm{R}^{2} 0.9988,1.36 \%, 98.8 \%, 0.750 \mathrm{ppm}$ and $1.073 \mathrm{ppm}$, respectively. These values were determined using internationally recognised guidelines for the validation of non-standard analytical methods, which means that our method can be applied to the different validation requirements of regulatory agencies and countries. Our method can be used for experimental conditions that require detection at low and high concentrations simultaneously because it is accurate, fast ( $0.6 \mathrm{~min}$ ) and repeatable across a concentration range of 1 to $40,000 \mathrm{ppm}$. This method will help to standardise the quantification of EDN by research groups and facilitate acceptance of data by regulatory organisations around the world.
\end{abstract}

Keywords: cyanogen; EDN Fumigas ${ }^{\mathrm{TM}}$; quarantine; soil; Sterigas $1000^{\mathrm{TM}}$; method validation

\section{Introduction}

Fumigants are commonly used to disinfest commodities of insects and pathogens prior to export. There are several fumigants which have been extensively tested and are globally used as quarantine and pre-shipment (QPS) treatments of forest products, including methyl bromide, sulfuryl fluoride and phosphine which have been found to be highly effective against pests of logs and wood packaging material [1,2]. However, the continued use of some of these chemicals has negative environmental consequences as methyl bromide depletes the ozone and sulfuryl fluoride is a greenhouse gas [3]. The long-term future of methyl bromide and sulfuryl fluoride as QPS treatments of forest products is therefore uncertain [4].

Since these fumigants have been widely used in international trade for decades, validated analytical methods for their quantification in air have already been established [5]. Ethanedinitrile (EDN) is a new fumigant being trialled as a chemical disinfestation treatment to replace methyl bromide. It was recently registered in Australia as a treatment for logs and sawn timber moved between states [6], and became available for testing in New Zealand in 2011 [7]. Studies which have evaluated the toxicity of EDN to insect pests have used various analytical techniques (Table 1), however, to our knowledge, there does not exist a standardised technique for accurately quantifying EDN. 
Recent studies have typically assessed the effectiveness of EDN in three core areas: (a) soil fumigation [8-10], (b) the treatment of fruits and vegetables [11], and (c) timber and logs [12-14]. Further development of EDN for these applications is currently focused on the treatment of soil and wood, as the use of EDN at low concentrations appears to be phytotoxic in fruits and vegetables [11]. As EDN is being trialled around the world as a new disinfestation treatment and as an alternative fumigant to methyl bromide for timber exports, a fast, accurate and repeatable method for its quantification is urgently required.

A significant advantage to using EDN as a fumigant is that, unlike the fumigants methyl bromide or sulfuryl fluoride, EDN is neither an atmospheric ozone depleting molecule nor is it a greenhouse gas $[15,16]$.

The mode of action for insects is thought to be like that of other inorganic cyanides, whereby EDN reduces to cyanide which interrupts the cytochrome c oxidase complex within the organism [17]. This leads to the inability to transport oxygen throughout the body, resulting in respiratory inhibition and ultimately asphyxiation or suffocation.

Quantifying the concentration of EDN in air may seem straightforward, as an EDN flame burns at $4,525^{\circ} \mathrm{C}$ [18]. Hence, a number of analytical techniques have been used, of which gas chromatograph with a flame ionization detector (GC-FID) is the most common (Table 1).

Table 1. List of recent studies (most recent to oldest) which quantify ethanedinitrile in air and their respective detection methods, columns and concentration ranges.

\begin{tabular}{|c|c|c|c|}
\hline Authors & Detection Method & Column & Concentration Range (ppm) ${ }^{a}$ \\
\hline Lee et al. [13] & GC-FID ${ }^{b}$ & $\mathrm{HP}-5$ & $0-20,000$ \\
\hline Najar-Rodriguez et al. [14] & GC-FID & GS-Q & $0-25,000$ \\
\hline Hall et al. [12] & GC-FID & GS-Q & $0-25,000$ \\
\hline Emery et al. [19] & GC-FID & GS-Q & $0-20,000$ \\
\hline Park et al. [20] & GC-FID & $\mathrm{HP}-5$ & $0-75,000$ \\
\hline Pranamornkith et al. [21] & GC-FID & GS-Q & $0-25,000$ \\
\hline Ren et al. [2] & GC-NPD ${ }^{c}$ & GS-Q̂े & $0-25,000$ \\
\hline Cho et al. [22] & GC-FID & DB-WAX & $0-40,000$ \\
\hline Park et al. [23] & GC-FID & DB-WAX & $0-20,000$ \\
\hline Ren et al. [24] & XK-3-TCD ${ }^{d}$ & - & $0-10,000$ \\
\hline Sarwar et al. [25] & GC-NPD ${ }^{\mathrm{e}}$ & $\mathrm{J} \& W$ & $0-50,000$ \\
\hline O'Brien et al. [26] & GC-NPD ${ }^{\text {e }}$ & DB-WAX & $0-20,000$ \\
\hline
\end{tabular}

\footnotetext{
${ }^{a}$ Unless stated within the publication(s), the concentration range is the minimum and maximum recordings observed

b GC-FID, gas chromatograph with a flame ionization detector

${ }^{c}$ GC-NPD, gas chromatograph with a nitrogen phosphorus detector

d XK-3-TCD, XK-3 fumigant monitor with a thermal conductivity detector

e Reported as GC-TSD, gas chromatograph with thermionic sensitive detector also known as NPD.
}

Of the twelve most recently published studies relating to fumigation science and the measurement of EDN, eight of them used a GC-FID method, and four used a gas chromatograph with a nitrogen phosphorus detector (GC-NPD) or a fumigant monitor fitted with a thermal conductivity detector (TCD) (Table 1). The columns used for separation with the most common GC-FID method are HP5, GS-Q and DB-WAX (Table 1), which are all general-purpose columns for the separation of a wide range of analytes. Four out of the eight GC-FID methods have used a GS-Q column for the separation of EDN. Therefore, the most common method of quantifying EDN in air for fumigation research is with GC-FID using a GS-Q column. This is a porous polymer, fused silica PLOT (porous layer open tubular) column and is designed for the separation of smaller molecules, such as EDN.

The aim of our study was to propose and validate an accurate, fast and repeatable analytical method to quantify EDN across a wide range of concentrations that would support fumigant research and ensure the integrity of analytical data. In addition, regulatory agencies require validation of any non-standard analytical method to accept physicochemical, toxicological and ecotoxicological data supplied as part of the chemical registration process. We provide here the data necessary to 
validate a method for the quantification of EDN in air that can be used universally and the results accepted internationally.

\section{Materials and Methods}

\subsection{Preparation of Samples}

The EDN Fumigas ${ }^{\mathrm{TM}}$ used in these tests was drawn from stocks held at the Plant \& Food Research disinfestation laboratory (Palmerston North, New Zealand). The Manufacturer's Certificate of Analysis (CoA) for the EDN used certified that the cylinders contained $98.32 \%$ EDN, $0.25 \%$ hydrogen cyanide and other unspecified impurities. EDN was dispensed from a high-pressure cylinder into a 20-L Tedlar ${ }^{\circledR}$ bag (SKC Ltd., Dorset, UK). Concentrations of EDN were then prepared in 1-L Tedlar bags using airtight gas syringes (Hamilton ${ }^{\circledR}$, Reno, Nevada, NV, USA), a $3 \mathrm{~mL}$ sample was then injected into the GC with a $250 \mu \mathrm{L}$ sample loop (Table 2).

Table 2. Instrument and conditions under which the proposed method for quantifying ethanedinitrile in air was validated.

\begin{tabular}{cc}
\hline Variable & Parameter \\
\hline Laboratory temperature & $25 \pm 1{ }^{\circ} \mathrm{C}$ \\
Column & Agilent J\&W GS-Q \\
Column dimensions & Length $30 \mathrm{~m}$, internal diameter $0.53 \mathrm{~mm}$, film thickness $0 \mathrm{~mm}$ \\
Carrier gas & Helium \\
Pressure & $27 \mathrm{psi}$ \\
Total flow & $239.79 \mathrm{~mL} / \mathrm{min}$ \\
Split ratio & $3 \mathrm{~mL}(250 \mu \mathrm{L})$ \\
Injection volume (sample loop volume) & $5: 1 @ 197.32 \mathrm{~mL} / \mathrm{min}$ \\
Temperature program & Isothermal $150^{\circ} \mathrm{C}$ \\
Detector temperature & $300^{\circ} \mathrm{C}$ \\
Inlet temperature & $150{ }^{\circ} \mathrm{C}$ \\
H flow & $100 \mathrm{~mL} / \mathrm{min}$ \\
Air flow & $400 \mathrm{~mL} / \mathrm{min}$ \\
Makeup flow (nitrogen) & $0.5 \mathrm{~mL} / \mathrm{min}$ \\
Total runtime & $0.6 \mathrm{~min}$ \\
\hline
\end{tabular}

\subsection{Analytical Conditions and Equipment}

Gas samples were analysed by gas chromatography using an Agilent 7890A (Santa Clara, CA, USA) equipped with a FID. The conditions under which the method was validated are described in Table 2. Peak integration was performed using ChemStation software, Agilent Technologies (Sanata Clara, CA, USA).

\subsection{Validation Guidelines}

To validate our method we followed the guidelines outlined by the International Council for Harmonisation of Technical Requirements for Pharmaceuticals for Human Use (ICH) [27], European Commission-Technical Materials and preparations (EC) [28] and the Australian Pesticides and Veterinary Medicines Authority (APVMA) [29]. These guidelines are recognised methods for the validation of non-standard analytical methods. The calculation of parameters from these guidelines include, but are not exclusive to, linearity, precision, accuracy, limit of detection (LOD) and limit of quantification (LOQ).

\subsection{Linearity}

The ability to produce test results that are proportional to the concentration of the analyte in samples must be tested within $80-120 \%$ of the anticipated concentration range. A correlation coefficient $\left(R^{2}\right)$ of $\geq 0.99$ must be achieved with a linear response across 6-8 concentrations for the method to 
meet the linearity criterion. Linearity was determined across seven concentrations $(0,5,000,10,000$, $15,000,20,000,25,000$ and 40,000 ppm) of EDN in air. The average response of the instrument to five replicates at each concentration was determined.

\subsection{Precision}

Precision was assessed by measuring the repeatability of the instrument across six concentrations of EDN in air that are typically used for fumigation research, with five replicates per concentration. Precision was measured by calculating the standard deviation (SD), percent standard error (\%SE) and percent relative standard deviation (\%RSD) of each concentration relative to the average. An average precision of $\leq 2 \%$ must be achieved to meet the ICH, EC and APVMA guidelines.

\subsection{Accuracy}

Accuracy is expressed as the degree to which the determined value of an analyte in a sample corresponds to a true value. To evaluate the accuracy of a method, guidelines require that a mean recovery of $98-102 \%$ is achieved.

\subsection{Limit of Detection}

The LOD is the lowest amount of an analyte that can be detected reliably against a blank sample, but not necessarily quantified as an exact value. The LOD or detection limit (DL) is calculated differently for ICH and APVMA guidelines, and both approaches were used (Table 3). EC guidelines do not clearly define how the LOD should be calculated.

Table 3. Accepted methods for calculating the limit of detection (LOD) or detection limit (DL).

\begin{tabular}{|c|c|}
\hline APVMA $^{a}$ & $\mathrm{ICH}^{\mathrm{b}}$ \\
\hline $\begin{array}{l}\text { The LOD of an analytical method is the lowest } \\
\text { amount of an analyte in a sample that can be detected, } \\
\text { but not necessarily quantified as an exact value. }\end{array}$ & $\begin{array}{c}\text { The DL of an individual analytical procedure is the } \\
\text { lowest amount of analyte in a sample which can be } \\
\text { detected but not necessarily quantified as an exact } \\
\text { value. }\end{array}$ \\
\hline $\mathrm{LOD}=\mathrm{X}+(3 \mathrm{SD})$ & $\mathrm{DL}=\frac{3.3 \mathrm{SD}}{\mathrm{b}}$ \\
\hline$X=$ Average response & $\mathrm{b}=$ slope of the calibration curve \\
\hline $\mathrm{SD}=$ The standard deviation of the response & $\mathrm{SD}=$ standard deviation of the response \\
\hline
\end{tabular}

\subsection{Limit of Quantification}

The LOQ or quantification limit (QL) is the lowest concentration of an analyte that can be quantified in a sample and was calculated using ICH and APVMA guidelines (Table 4); while the EC guidelines do not state how LOQ is to be calculated. 
Table 4. Accepted methods for calculating the limit of quantification (LOQ) or quantification limit (QL).

\begin{tabular}{|c|c|c|}
\hline APVMA $^{\mathbf{a}}$ & $\mathrm{ICH}^{\mathrm{b}}$ & $\mathrm{EC}^{\mathrm{c}}$ \\
\hline $\mathrm{LOD}=\mathrm{X}+(10 \mathrm{SD})$ & $\mathrm{QL}=\frac{10 \mathrm{SD}}{\mathrm{b}}$ & ${ }^{* *}$ Not given \\
\hline $\begin{array}{c}\mathrm{X}=\text { Average response } \\
\mathrm{SD}=\text { The standard deviation of } \\
\text { the response }\end{array}$ & $\begin{array}{c}\mathrm{B}=\text { slope of the calibration curve } \\
\mathrm{SD}=\text { standard deviation of the } \\
\text { response }\end{array}$ & \\
\hline
\end{tabular}

\section{Results}

\subsection{Linearity}

The linearity of EDN was determined across seven concentrations (0, 5000, 10,000, 15,000, 20,000, 25,000 and 40,000 ppm) using the average of five replicates at each concentration. The response of the instrument was linear with an $\mathrm{R}^{2}$ value of $0.9988(\mathrm{y}=0.3693 \mathrm{x})$ ), indicating that the linearity of this method passed all of the guidelines [2-9].

\subsection{Precision}

Precision of the method was determined by the analysis of six concentrations ranging from 25 to $200 \%$ of the expected concentration range. The response of the instrument under the conditions tested is summarised in Table 5.

Table 5. Response of the instrument to different concentrations of ethanedinitrile to determine linearity and precision of the analytical method.

\begin{tabular}{ccccccccc}
\hline & \multicolumn{7}{c}{ Peak Area } & \\
Conc. (ppm) & Rep. 1 & Rep. 2 & Rep. 3 & Rep. 4 & Rep. 5 & Average & \%SE $^{\mathbf{a}}$ & \%RSD $^{\mathbf{b}}$ \\
\hline 5000 & 2024 & 2010 & 2084 & 2154 & 2105 & 2075.19 & 1.146 & 2.56 \\
10,000 & 3988 & 4038 & 3932 & 3966 & 3976 & 3979.95 & 0.389 & 0.87 \\
15,000 & 5459 & 5308 & 5390 & 5361 & 5447 & 5392.94 & 0.463 & 1.03 \\
20,000 & 7095 & 7291 & 7319 & 7368 & 7284 & 7271.45 & 0.573 & 1.28 \\
25,000 & 9383 & 9133 & 9180 & 9391 & 9365 & 9290.39 & 0.533 & 1.19 \\
40,000 & 14,527 & 14,719 & 14,735 & 15,034 & 14,723 & $14,747.40$ & 0.493 & 1.10 \\
Average & - & - & - & - & - & - & 0.607 & 1.36 \\
\hline
\end{tabular}

${ }^{a}$ Percentage standard error of the peak area

$\mathrm{b}$ Percentage relative standard deviation

The average RSD across the concentration range tested was 1.36\% (Table 5), which meets the requirement of $\leq 2 \%$ defined by the ICH and APVMA guidelines for precision [27,29].

\subsection{Accuracy}

Accuracy was measured by establishing three concentrations (15,000, 20,000 and 25,000 ppm) that correspond to between 80 and $120 \%$ of the expected concentration range and collecting five replicate samples of each concentration. 
The average accuracy of the GC-FID method was calculated by combining the average response of five replicates across three concentrations. The average accuracy of the method under the conditions tested was $98.8 \%$ (Table 6). This meets the accuracy requirement of $98-102 \%$ specified by respective guidelines [27-29].

Table 6. Measured peak area of the instrument to different concentrations of ethanedinitrile to determine accuracy of the method.

\begin{tabular}{ccccccccc}
\hline Conc. (ppm) & Rep. 1 & Rep. $\mathbf{2}$ & Rep. 3 & Rep. 4 & Rep. 5 & Average & Conc. (ppm) ${ }^{\mathbf{a}}$ & Accuracy $^{\mathbf{b}}$ \\
\hline 15,000 & 5459 & 5308 & 5390 & 5361 & 5447 & 5392.943 & $14,603.31$ & 97.4 \\
20,000 & 7095 & 7291 & 7319 & 7368 & 7284 & 7271.45 & $19,690.04$ & 98.5 \\
25,000 & 9383 & 9133 & 9180 & 9391 & 9365 & 9290.393 & $25,157.05$ & 100.6 \\
Average & - & - & - & - & - & - & - & 98.8 \\
\hline
\end{tabular}

${ }^{\mathrm{a}}$ Concentration calculated from standard curve equation, calculated concentration (ppm)

${ }^{\mathrm{b}}$ Accuracy was calculated as a ratio of the calculated concentration/concentration to give a precision percentage

\subsection{Limit of Detection and Limit of Quantification}

The LOD and LOQ of the method were determined by repeated measurements of the lowest repeatable concentration of EDN at 10 different instances (Table 7). The average measured concentration and \%RSD are presented in Table 7 . With the formulae presented in Tables 3 and 4 , these data were used to calculate the LOD and LOQ of the method.

Table 7. Data used to calculate the limit of detection and limit of quantification of a GC-FID method used to measure ethanedinitrile in air.

\begin{tabular}{cc}
\hline Rep. & Conc. (ppm) \\
\hline 1 & 0.636 \\
2 & 0.565 \\
3 & 0.693 \\
4 & 0.566 \\
5 & 0.597 \\
6 & 0.542 \\
7 & 0.620 \\
8 & 0.659 \\
9 & 0.653 \\
10 & 0.583 \\
Average & 0.611 \\
SD & a \\
\%RD & 0.046 \\
b & 7.543 \\
\hline a Standard deviation \\
b Percentage relative standard deviation
\end{tabular}

\subsubsection{LOD Calculation}

Using the formulae in Table 3 and the data in Table 7, the LOD was 0.750 and 0.138 ppm using the APVMA and the ICH guidelines, respectively.

\subsubsection{LOQ Calculation}

Using the formulae in Table 4 and data in Table 7, the LOQ was 1.073 and 0.461 ppm using the APVMA and the ICH guidelines, respectively.

The chromatograms in Figure 1 display the typical response for different concentrations of EDN. No other eluents are seen later in the run for high concentrations although a back flash of EDN is seen following the initial peak. This is common with methods that use a high flow rate and a faster run time [30]. This anomaly was validated as a back flash and not as a later eluent from a previous 
run (data not shown). Concentrations are calculated from the area under the curve by using defined cardinal points divided by the slope of the calibration curve.

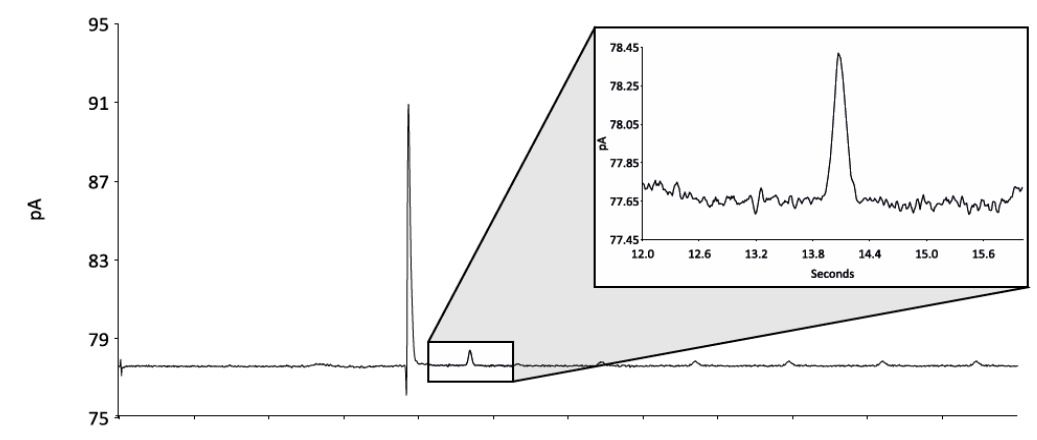

(a)

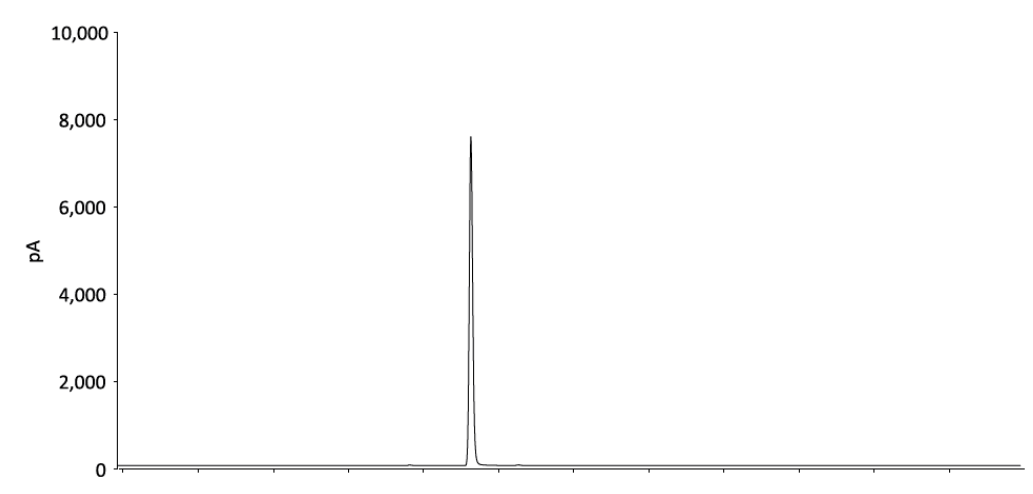

(b)

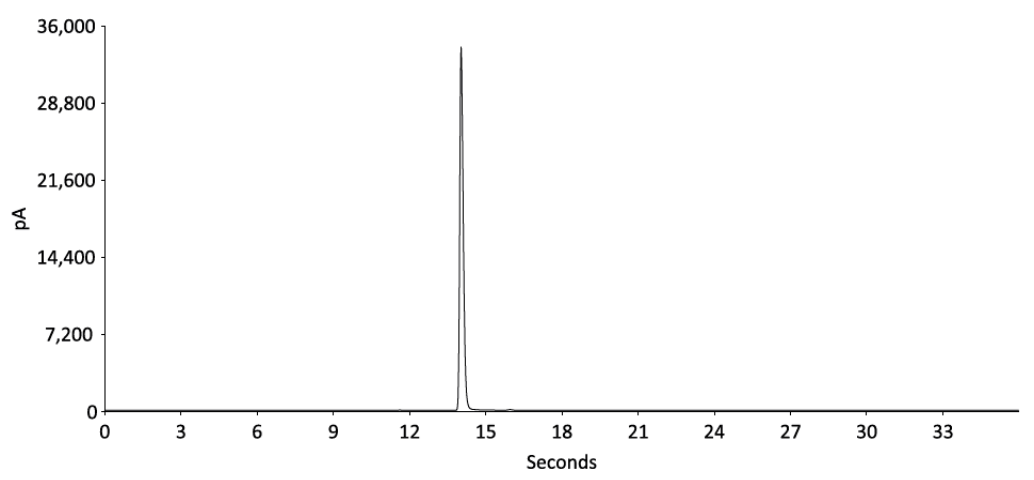

(c)

Figure 1. Chromatograms for three different concentrations of ethanedinitrile (a) low: $0.6 \mathrm{ppm}$, (b) medium: 5,000 ppm and (c) high: 25,000 ppm and their relative intensities.

\section{Discussion}

Research activities with EDN that produce physicochemical, toxicological and ecotoxicological data must meet the requirements of regulatory agencies of different countries. An important step in this process is the validation of non-standard analytical methods that use guidelines which specify the minimum requirements across a range of factors to determine the quality of the method.

EDN is a relatively new fumigant that is being trialled around the world as a disinfestation treatment of soil and wood products prior to commercialisation. There is a range of analytical methods currently being used to measure EDN across research groups, with differences in the detection method and column used for separation (Table 1). Because the most common method of detection in published 
literature uses GC-FID with a GS-Q column, we have developed and validated an analytical method to measure EDN using this equipment.

Here we present and validate an accurate, fast and repeatable method for the quantification of EDN in air. Acceptable values for the parameters (linearity, precision, accuracy, LOD and LOQ) of three internationally accepted guidelines [27-29] were met. Unfortunately, comparisons between our method and those used by other studies are not possible, as this is the first time that a validated methodology to quantify the concentration of EDN in air has been proposed. It was not the focus of this work to test field collected samples, however, a number of studies $[12,14,21]$ have used the same method and shown that it performs very well under these conditions. These studies did not go the extent of validating the method, as this work has done, but they indicate that the method is not affected by the coelution of other compounds during simulated commercial fumigations.

\section{Conclusion}

Our method is suitable for all EDN fumigation studies that require detection at low and high concentrations simultaneously. Our hope is that this method is used by researchers to standardise the way in which EDN is quantified during and after fumigation to facilitate the acceptance of data by regulatory authorities around the world.

Author Contributions: Conceptualisation, S.E.B., A.R.A and M.K.D.H; Methodology, S.E.B., A.R.A and M.K.D.H; Validation, S.E.B., A.R.A and M.K.D.H; Formal Analysis, S.E.B and M.K.D.H; Resources, M.K.D.H; Data Curation, S.E.B and A.R.A; Writing-Original Draft Preparation, S.E.B., A.R.A and M.K.D.H; Project Administration, M.K.D.H; Funding Acquisition, M.K.D.H.

Funding: This work was supported by Stakeholders in Methyl Bromide Reduction (STIMBR) and The Draslovka Group.

Acknowledgments: Scientific inputs of Pranoy Pal are greatly appreciated.

Conflicts of Interest: The authors declare no conflict of interest.

\section{References}

1. Barak, A.V.; Wang, Y.; Zhan, G.; Wu, Y.; Xu, L.; Huang, Q. Sulfuryl fluoride as a quarantine treatment for Anoplophora glabripennis (Coleoptera: Cerambycidae) in regulated wood packing material. J. Econ. Entomol. 2006, 99, 1628-1635. [CrossRef] [PubMed]

2. Ren, Y.; Lee, B.; Padovan, B. Penetration of methyl bromide, sulfuryl fluoride, ethanedinitrile and phosphine into timber blocks and the sorption rate of the fumigants. J. Stored Prod. Res. 2011, 47, 63-68. [CrossRef]

3. Sulbaek Andersen, M.P.; Blake, D.R.; Rowland, F.S.; Hurley, M.D.; Wallington, T.J. Atmospheric chemistry of sulfuryl fluoride: Reaction with $\mathrm{OH}$ radicals, $\mathrm{Cl}$ atoms and $\mathrm{O}_{3}$, atmospheric lifetime, IR spectrum, and global warming potential. Environ. Sci. Technol. 2009, 43, 1067-1070. [CrossRef]

4. UNEP. Handbook for the Montreal Protocol on Substances that Deplete the Ozone Layer, 10th ed.; Secretariat of The Vienna Convention for the Protection of the Ozone Layer \& The Montreal Protocol on Substances that Deplete the Ozone Layer: Nairobi, Kenya, 2016. Available online: http:/ /www.efcc.eu/media/1079/2016ods-montreal_protocol-handbook.pdf (accessed on 15 December 2018).

5. Park, H.; Kim, H.; Kwon, J.-E.; Yoon, J.-Y.; Lee, J.-Y.; Chang, M.-I.; Rhee, G.-S. Development and validation of an analytical method for quantification of sulfuryl fluoride residues in agricultural products using gas chromatography with electron capture detection. Food Sci. Biotechnol. 2014, 23, 1799-1804. [CrossRef]

6. BOC. BOC Field Trial Report_Ethanedinitrile Fumigant (EDN) Worker Exposure Field Trial, Timber Application under Tarp; BOC Australia: North Ryde, NSW, Australia, 2013.

7. NZ-EPA. ERMA200981 Decision-Approval of Ethanedinitirle for Use in Containments; New Zealand Environmental Protection Authority: Wellington, New Zealand, 2011. Available online: https://www. epa.govt.nz/assets/FileAPI/hsno-ar/ERMA200981/ERMA200981-ERMA200981-Decision.pdf. (accessed on 15 December 2018).

8. Caddick, L. Search for methyl bromide and phosphine alternatives. Outlooks Pest Manag. 2004, 15, 118-119. [CrossRef] 
9. Mattner, S.; Gounder, R.; Mann, R.; Porter, I.; Matthiessen, J.; Ren, Y.; Sarwar, M. Ethanedinitrile $\left(\mathrm{C}_{2} \mathrm{~N}_{2}\right)-\mathrm{A}$ novel soil fumigant for strawberry production. Acta Hortic. 2004, 708. [CrossRef]

10. Mattner, S.; Gregorio, R.; Ren, Y.; Hyland, T.; Gounder, R.; Sarwar, M.; Porter, I.J. Application techniques influence the efficacy of ethanedinitrile $\left(\mathrm{C}_{2} \mathrm{~N}_{2}\right)$ for soil disinfestation. In Proceedings of the Annual International Research Conference on Methyl Bromide Alternatives and Emission Reductions, San Diego, CA, USA, 3-6 November 2003. Available online: https:/ / www.mbao.org/static/docs/confs/2003-sandiego/ papers /127\%20mattnerssummary\%20-\%20mattner\%20poster.pdf (accessed on 15 December 2018).

11. Jessup, A.J.; Golding, J.G. Qfly Proof of Concept for Ethane Dinitrile (EDN) Fumigation; Horticulture Australia Pty Ltd.: Sydney, Australia, 2012.

12. Hall, M.; Najar-Rodriguez, A.; Pranamornkith, T.; Adlam, A.; Hall, A.; Brash, D. Influence of dose, bark cover and end-grain sealing on ethanedinitrile $\left(\mathrm{C}_{2} \mathrm{~N}_{2}\right)$ sorption by pine (Pinus radiata $\mathrm{D}$. Don) $\operatorname{logs}$. N. Z. Plant Prot. 2015, 68, 13-18.

13. Lee, B.-H.; Yang, J.-O.; Beckett, S.; Ren, Y. Preliminary trials of ethanedinitrile $\left(\mathrm{C}_{2} \mathrm{~N}_{2}\right)$ fumigation of logs for eradication of Bursaphelenchus xylophilus and its vector insect Monochamus alternatus. Pest Manag. Sci. 2017. [CrossRef] [PubMed]

14. Najar-Rodriguez, A.; Hall, M.; Adlam, A.; Hall, A.; Burgess, S.; Somerfield, K.; Page, B.B.C.; Brash, D.W. Developing new fumigation schedules for the phytosanitary treatment of New Zealand export logs: Comparative toxicity of two fumigants to the burnt pine longhorn beetle, Arhopalus ferus. N. Z. Plant Prot. 2015, 68, 19-25.

15. Hall, M.; Najar-Rodriguez, A.; Adlam, A.; Hall, A.; Brash, D. Sorption and desorption characteristics of methyl bromide during and after fumigation of pine (Pinus radiata D. Don) logs. Pest Manag. Sci. 2017, 73, 874-879. [CrossRef] [PubMed]

16. Minini, K.M.S.; Bueno, S.C.E.; da Silva, M.G.; Sthel, M.S.; Vargas, H.; Angster, J.; Miklós, A. Quantum cascade laser-based photoacoustic sulfuryl fluoride sensing. Appl. Phys. B 2017. [CrossRef]

17. Hamel, J. A review of acute cyanide poisoning with a treatment update. Crit. Care Nurse 2011, 31, 72-82. [CrossRef] [PubMed]

18. Conway, J.; Wilson, R., Jr.; Grosse, A. The temperature of the cyanogen-oxygen flame. J. Am. Chem. Soc. 1953, 75, 499-499. [CrossRef]

19. Emery, R.; Ren, Y.; Newman, J.; Thalavasundaram, S. Evaluation of ethanedinitrile (EDN) as a methyl bromide alternative for eradication of European House Borer (EHB). In Proceedings of the 11th International Working Conference on Stored Product Protection, Chiang Mai, Thailand, 24-28 November 2014; Arthur, F.H., Kengkanpanich, R., Chayaprasert, W., Suthisut, D., Eds.; pp. 942-949.

20. Park, C.G.; Son, J.-K.; Lee, B.-H.; Cho, J.H.; Ren, Y. Comparison of ethanedinitrile $\left(\mathrm{C}_{2} \mathrm{~N}_{2}\right)$ and metam sodium for control of Bursaphelenchus xylophilus (Nematoda: Aphelenchidae) and Monochamus alternatus (Coleoptera: Cerambycidae) in naturally infested logs at low temperatures. J. Econ. Entomol. 2014, 107, 2055-2060. [CrossRef] [PubMed]

21. Pranamornkith, T.; Hall, M.; Adlam, A.; Somerfield, K.; Page, B.; Hall, A.; Brash, D.W. Effect of fumigant dose, timber moisture content, end-grain sealing, and chamber load factor on sorption by sawn timber fumigated with ethanedinitrile. N. Z. Plant Prot. 2014, 67, 66-74.

22. Cho, D.; Moon, Y.; Choi, M.; Shin, C.; Lee, B.; Ren, Y. Efficacy of ethanedinitrile to wood relating pests: Japanese Termite and Yellow Minute Bark Beetles. In Proceedings of the Annual International Research Conference on Methyl Bromide Alternatives and Emissions Reductions, San Diego, MA, USA, 31 October-2 November 2011.

23. Park, M.; Sung, B.; Hong, K.; Lee, B.; Ren, Y. The efficacy of ethanedinitrile to control wood related insect pests. In Proceedings of the Annual International Research Conference on Methyl Bromide Alternatives and Emissions Reductions, San Diego, MA, USA, 29 October-1 November 2007.

24. Ren, Y.; Wang, Y.; Barak, A.V.; Wang, X.; Liu, Y.; Dowsett, H.A. Toxicity of ethanedinitrile to Anoplophora glabripennis (Coleoptera: Cerambycidae) larvae. J. Econ. Entomol. 2006, 99, 308-312. [CrossRef] [PubMed]

25. Sarwar, M.; Mahon, D.; Ren, Y. Interaction of ethanedinitrile $\left(\mathrm{C}_{2} \mathrm{~N}_{2}\right)$ with contact materials used in grain storage. In Proceedings of the Proceedings of the Australian Postharvest Technical Conference, Canberra, Australia, 25-27 June 2003.

26. O'Brien, I.G.; Desmarchelier, F.J.M.; Yonglin, R. Cyanogen Fumigants and Methods of Fumigation Using Cyanogen. U.S. Patents CA2192959A1, 14 December 1999. 
27. ICH. Validation of Analytical Procedures: Text and Methodology. 1995. Available online: https://www.ich.org/fileadmin/Public_Web_Site/ICH_Products/Guidelines/Quality/Q2_R1/Step4/ Q2_R1_Guideline.pdf (accessed on 15 December 2018).

28. EC. Technical Material and Preparations: Guidance for Generating and Reporting Methods of Analysis in Support of Pre- and Post-Registration Data Requirements for Annex II (Part A, Section 4) and Annex III (Part A, Section 5) of Directive 91/414. 1996. Available online: https: / / ec.europa.eu/food/sites / food / files / plant/ docs/pesticides_ppp_app-proc_guide_phys-chem-ana_tech-mat-preps.pdf (accessed on 15 December 2018).

29. APVMA. Guidelines for the Validation of Analytical Methods for Active Constituent, Agricultural and Veterinary Chemical Products. 2004. Available online: http://apvma.gov.au/sites/default/files/docs/ guideline-69-analytical-methods.pdf (accessed on 15 December 2018).

30. Kuhn, E.R. Water injections in GC-How wet can you get? LCGC Asia Pac. 2002, 5, 30-32.

(C) 2018 by the authors. Licensee MDPI, Basel, Switzerland. This article is an open access article distributed under the terms and conditions of the Creative Commons Attribution (CC BY) license (http:/ / creativecommons.org/licenses/by/4.0/). 